\title{
Solid-State Lighting
}

\section{Multi-Year \\ Market Development Support Plan}

May 2012

Prepared for:

Solid-State Lighting Program

Building Technologies Program

\begin{tabular}{l|l} 
U.s. DEPARTMENT of & $\begin{array}{l}\text { Energy Efficiency \& } \\
\text { ENenewable Energy }\end{array}$
\end{tabular} 


\section{Contents}

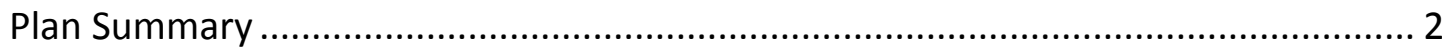

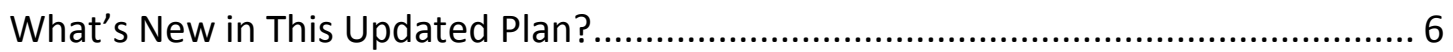

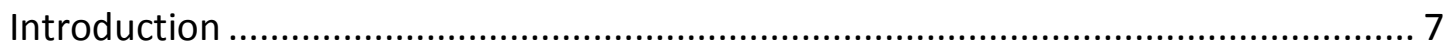

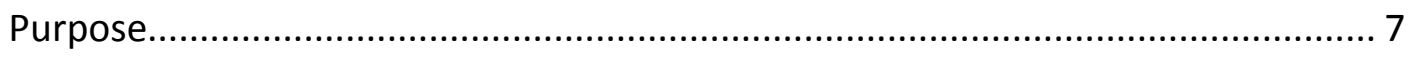

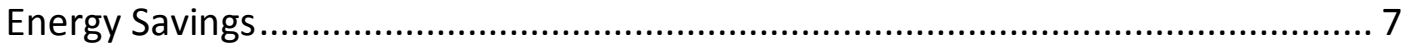

DOE Role in SSL Market Development Support .............................................. 7

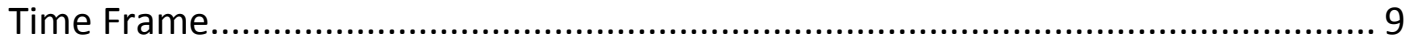

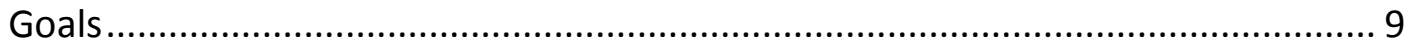

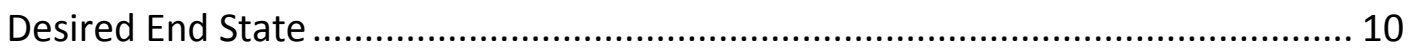

Market Barriers Addressed by Plan................................................................ 11

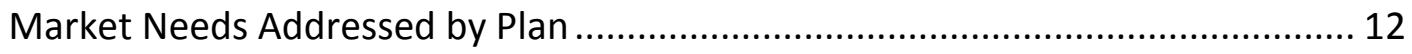

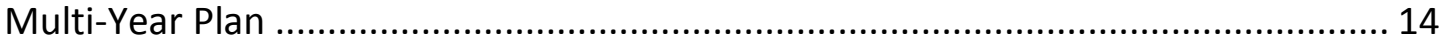

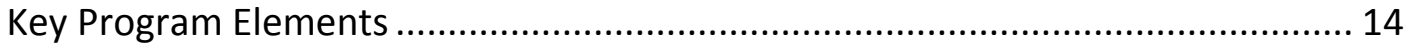

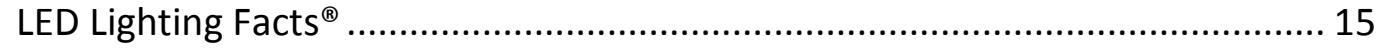

Next Generation Luminaires ${ }^{\mathrm{TM}}$ Design Competition ........................................ 18

GATEWAY Technology Demonstrations ......................................................... 19

Commercially Available LED Product Evaluation and Reporting (CALIPER) ........ 21

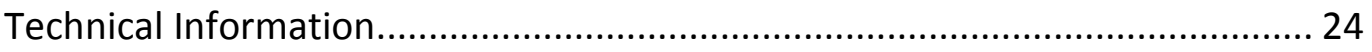

Standards and Test Procedures Support .......................................................... 28

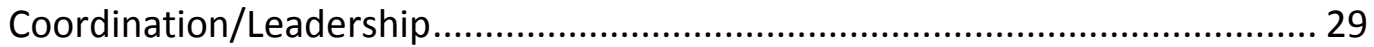

Market Studies and Technology Evaluations ................................................. 31

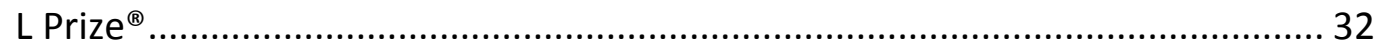

Key Issues to Be Addressed in Project Development........................................... 35

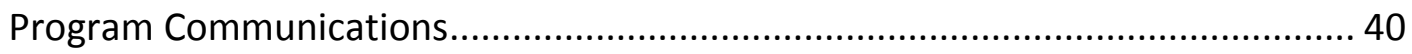

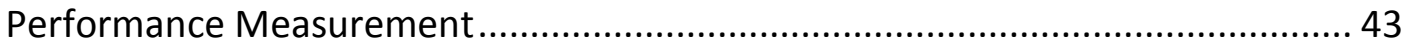

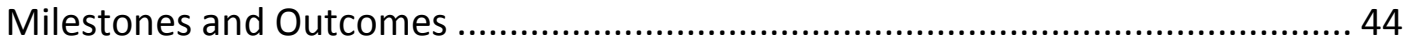

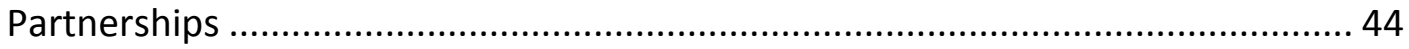

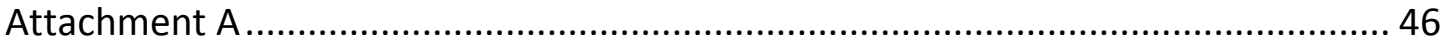

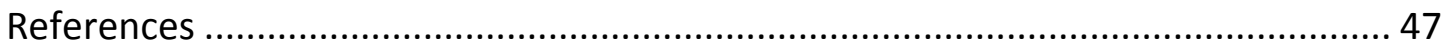


This plan sets out a strategic, five-year framework for guiding DOE's market development support activities for high-performance solid-state lighting (SSL) products for the U.S. general illumination market. The market development support activities described in this plan, which span federal fiscal years 2012 to 2016, are intended to affect the types of SSL general illumination products adopted by the market, to accelerate commercial adoption of those products, and to support appropriate application of those products to maximize energy savings.

DOE has established aggressive FY16 goals for these activities, including goals for the types of products brought to market, the market adoption of those products, and the energy savings achieved through use of SSL products. These goals are for the combined effect of DOE's SSL market development support and R\&D investment, as well as the leveraged activities of its partners. Goals include 1) inducing the market introduction of SSL products achieving 112 lumens per Watt (Im/W) for warm white products, and 131 $\mathrm{Im} / \mathrm{W}$ for cool white products, and 2 ) inducing sales of high-performance SSL products that achieve annual site electricity savings of 21 terawatt hours ( 0.25 quadrillion Btus primary energy) by FY16.

The plan identifies 10 key SSL market needs for DOE commercialization assistance. They are:

1) Effective product purchasing guidance for retailers, facility managers, other large volume buyers, consumers, and other agents that act on their behalf, such as lighting specifiers and electric utilities (to guide buyers to products that are likely to perform well)

2) Market visibility for high performance, commercially available products (to educate the market about the technical potential of the technology in welldesigned products)

3) Well-documented case studies of SSL general illumination installations (to inform the market about application issues, energy performance and cost effectiveness)

4) Market introduction support from energy efficiency program sponsors (to help SSL manufacturers build sales volume for high performance products, thereby increasing the demand for high performance products and driving down technology costs)

5) Independent performance test results on commercially available products (to counter exaggerated performance claims made by vendors, to encourage manufacturers to use industry standard test procedures as a basis for performance claims, and to provide a high quality dataset on product performance that can be used to analyze trends and product performance issues) 
6) Objective, widely available technical information from a credible, respected source (to help fill information gaps and increase understanding of the technology, its attributes, and its limitations)

7) Support for development of industry standards and test procedures for SSL general illumination products (to enable basic market infrastructure)

8) Coordination of local, regional, and federal SSL market development activities (to maximize effect of invested public and ratepayer money)

9) Independent investigations from a credible source of key SSL issues affecting market adoption of SSL (to provide up-to-date information on SSL market development for both DOE and industry planning and analysis purposes)

10) High visibility technology competitions (to spur innovation by reducing the risks of developing and selling very high performance, state-of-the-art, SSL products)

Meeting these market needs can collectively help drive down the costs of SSL by expanding market opportunities for high performance SSL, which in turn generates revenue for SSL manufacturers to invest in R\&D and lower-cost production. Further, meeting these market needs will help build an industry standards/test procedure infrastructure that is widely recognized and used, allowing manufacturers to characterize their products in terms clearly understood by potential buyers. And last, meeting these market needs helps equip lighting industry professionals, facility operators, lighting specifiers, energy efficiency program sponsors, retailers, and consumers with the information they need to make good purchasing decisions, and to properly apply this new technology.

To overcome the above identified market barriers and to achieve the above fiveyear goals, DOE proposes to carry out the following strategy.

DOE will implement a multi-year program to accelerate adoption of good quality, high performance SSL products that achieve significant energy savings and maintain or improve lighting quality. Relying on lessons learned from past emerging technology introductions, such as compact fluorescent lamps, and using newly developed market research, DOE will design its efforts to minimize the likelihood that the SSL market will repeat mistakes that greatly delayed market adoption of earlier emerging technology market introductions.

To achieve the maximum effect per dollar invested, DOE will work closely with lighting industry organizations - such as the Next Generation Lighting Industry Alliance, North American Illuminating Engineering Society, and the International Association of Lighting Designers - and with other government programs seeking to improve lighting energy efficiency. While DOE will work closely with these organizations and others from lighting and electric utility industry, the program will focus primarily on assisting buyers of SSL products and others acting on their 
behalf because satisfied buyers are essential to the success of SSL market adoption.

The work product of DOE's efforts will primarily be information, of the right type, at the right time, and provided efficiently to those who can best use it. A secondary work product of DOE's program will be market opportunities, in which DOE will seek to reduce the risks and costs for manufacturers of SSL products to sell good quality, high performance products to motivated buyers.

In short, DOE plans to implement a multi-year program that produces highly useful and widely available information for buyers and their agents, while producing important market opportunities for producers, avoids the mistakes of the past, and is closely coordinated with industry and government.

The market needs and the overall strategy were used for deciding which types of programs and projects DOE should create, and what general form they should take. Those projects and programs are identified in this plan as the plan's key program elements. They are:

\section{LED Lighting Facts ${ }^{\circledR}$}

- LED Lighting Facts

- SSL Quality Advocates

\section{Next Generation Luminaires ${ }^{\mathrm{TM}}$ Competition}

\section{GATEWAY Technology Demonstrations}

- Demonstrations

- Technology Demonstration Consortia, such as the Municipal Solid-State Street Lighting Consortium

\section{Commercially Available LED Product Evaluation and Reporting (CALiPER)}

\section{Technical Information}

- Technical Information Development and Dissemination

- Technical Information Network

\section{Standards and Test Procedures Support}

\section{Coordination/Leadership}

- Facilitating and Coordinating Local and Regional Efforts

- Federal Government Leadership

\section{Market Studies and Technology Evaluations}

Technology Prize Competitions (L Prize ${ }^{\circledR}$ ) 
The above nine program elements represent DOE's comprehensive approach to SSL market development support. They depend on active involvement from program partners, ranging from energy efficiency program sponsors, to industry associations, to standards setting bodies. The resources, expertise, and networks these program partners bring to the efforts represented by this plan greatly multiply any market development DOE can achieve on its own, and thus are a critical element to the success of this plan. Among DOE's key program partners are the Next Generation Lighting Industry Alliance, Illuminating Engineering Society of North America, International Association of Lighting Designers, and a large number of electric utilities, retailers, and energy efficiency organizations.

Progress toward achieving plan goals with the above program elements will be monitored and periodically reported. 


\section{What's New in This Updated Plan?}

In addition to a general update and rewrite of the plan, this new version contains the following significant changes:

- The Next Generation Luminaires Competition was split into two separate competitions, one for indoor products, and one for outdoor products.

- The Municipal Street Lighting Consortium, begun in FY10 using funding from the American Recovery and Reinvestment Act, has been incorporated into the GATEWAY program.

- CALIPER is now integrated with Lighting Facts. This was done to take advantage of the performance data being generated by the quality assurance testing on LED Lighting Facts products. These data are now being included in the dataset CALiPER uses to characterize the performance of commercially available products.

- DOE intends to makes its test results more easily accessible by the public after the integration with LED Lighting Facts is completed.

- The plan now reflects more emphasis on market research. Now that LEDs have established a foothold in the lighting market, there is much to learn about those early experiences that might help guide planning by DOE and others. In addition, DOE needs new and better information for targeting its activities under this plan.

- This plan increases the emphasis DOE is placing on addressing the needs of buyers. What information do they need to meet their needs?

- The plan reflects an effort to build knowledge bases and datasets that support improvements in the technology and its application. For example, DOE will create data sets on dirt depreciation that can be used to develop dirt depreciation factors for SSL, and flicker measurements that can be used to develop flicker standards and measurement methods.

- The performance goals were increased substantially, and aligned with the performance targets in the DOE SSL R\&D Multi-Year Plan.

- DOE's role in developing and implementing SSL ENERGY STAR ${ }^{\circledR}$ criteria was removed to reflect movement of that responsibility from DOE to EPA in 2010.

- The plan no longer reflects SSL's initial market introduction, and instead reflects the technology's market foothold, but continued need for intensive support.

- Standards activities now reflect DOE's intent to begin addressing OLED standards.

- More emphasis is placed on addressing the commercial and industrial sectors, with less on the residential sector.

- New attention is focused on investigating SSL as an enabling technology for reducing energy use, beyond that yielded by improved light source efficiency, such as energy savings enabled for lighting controls, stray light control in outdoor luminaires, improved roadway visibility, and others.

- A new effort to develop training materials for electricians and contractors is included, to help them overcome the installation problems they've encountered.

- More explicit treatment of LED replacement lamps was added, making clear DOE's intent to support increased market penetration of both LED replacement lamps and whole luminaires.

- A revised and updated communication strategy, intended to expand the audience being reached with SSL information. 


\section{Purpose}

The purpose of this plan is to set out a strategic, five-year framework for guiding DOE's market development support activities for high-performance SSL products for the U.S. general illumination market. The purpose of the market development support activities described in the plan is threefold. DOE plans to help remove the roadblocks that are slowing market adoption of SSL by helping create the conditions, specifications, standards, opportunities, information, and incentives that:

(1) affect the types of SSL general illumination products adopted by the market, emphasizing high-performance products likely to reduce energy use and satisfy users;

(2) accelerate commercial adoption of these products;

(3) support appropriate application of these products to maximize energy savings.

\section{Energy Savings}

DOE intends the sum of its efforts to shift the commercial adoption curve for highperformance SSL products ahead by five years, yielding large energy and economic savings. DOE estimates that annual energy savings from full implementation of this plan (in combination with its SSL R\&D plan) are 21 TWh (site electricity use), or 0.25 quadrillion Btus (primary energy use) by FY16. This is approximately equal to the annual electricity use in the state of New Mexico. These estimates are based on the savings estimates described in the most recent version of DOE's "Energy Savings Estimates of Light Emitting Diodes in General Illumination Applications," (DOE 2012b).

\section{DOE Role in SSL Market Development Support}

In considering the question of DOE's role to play in assisting with the market development of SSL, DOE first acknowledges the primary responsibility for commercializing advanced SSL technologies rests with the private sector. SSL system and component manufacturers are best positioned to decide how and when products are brought to market. However, DOE has a market development role for SSL, derived from explicit authority given DOE in Sec. 912 of EPAct 2005:

The Secretary [of Energy] shall carry out a Next Generation Lighting Initiative in accordance with this section to support research, development, demonstration, and commercial application activities 
related to advanced solid-state lighting technologies based on white light emitting diodes.

In addition, SSL market development activities are consistent with the May 2011 DOE Strategic Plan, in which Secretary Chu states,

"...the Department needs to cultivate the entire technology innovation chain, from enabling discoveries to research, development, demonstration, and deployment (RDD\&D)... To ensure our nation's future prosperity, the Department must identify and nurture promising technologies, even though some may falter for a variety of reasons unrelated to technical capability. In later stages of innovation, we must leverage our resources with those of the private sector to move promising technologies from the laboratory to the marketplace.

DOE is uniquely positioned to carry out these activities. First, DOE has a substantial SSL R\&D program that provides a strong technical basis from which to develop and implement an SSL market development support program (DOE 2012). SSL technology is fundamentally different from conventional lighting technologies. It requires different standards, methods of measurement, product integration, thermal design, optical design, and a range of different approaches for successful lighting application. All this makes a thorough understanding of SSL technology necessary for development and implementation of an appropriate and well-considered market development assistance program.

In addition, DOE's experience with a wide range of market development methods and programs, especially when coupled with its SSL technical understanding, make DOE the right agency to carry out this program. More specifically, DOE's value in helping commercialize SSL is based, in part, on the following:

- $\quad$ DOE and the federal government are valued by the public as being providers of unbiased, technically sound information. With the buying public holding a healthy skepticism about vendor product claims, SSL manufacturers value the credibility DOE can bring to this new market.

- DOE can influence federal purchasing. Many federal agencies look to DOE for assistance and advice on which new energy saving products to investigate and buy. Through FEMP, federal regulations, and a wide range of conferences and technical materials, DOE exerts important influence on what SSL products should be considered for purchase by other federal agencies.

- DOE can provide leadership to the industry, and serve as a focal point to catalyze private activity that competing companies may otherwise be reluctant to engage in. For example, SSL manufacturers now widely credit DOE with having successfully organized the industry into developing a wide ranging set of industry 
standards and test procedures for SSL application to the general illumination market.

- DOE can facilitate partnerships with a wide range of organizations that can influence the rate at which SSL products are accepted by the market. By working with electric utilities, non-profit organizations, state energy offices, trade associations and others, DOE can rally the assistance of organizations motivated to engage in activities that lead to efficiency improvements and energy savings.

DOE's role in SSL market development is widely recognized in the lighting industry. DOE entered into a Memorandum of Understanding with the Next Generation Lighting Industry Alliance (NGLIA) on February 2, 2005. The success of that agreement led to its updating and renewal in 2010.

DOE's role and value in SSL market development was also recognized by the Illuminating Engineering Society of North America (IES), with which DOE entered into a Memorandum of Understanding on July 17, 2006 to enhance, among other things, DOE's SSL market development support efforts. That agreement was renewed in October 2011, and extended through 2016.

DOE also entered into a Memorandum of Understanding with the International Association of Lighting Designers (IALD) on November 10, 2008, which included a commitment to assist the lighting design community in "the assessment and specification of solid state lighting..."

\section{Time Frame}

This plan addresses the period FY12 - FY16.

\section{Goals}

The goals of DOE's SSL market development support efforts for the five years covered by this plan are directly related to the purposes of these activities, as described in the above Purpose Section. They are to create and catalyze market conditions, specifications, standards, and market opportunities that influence products brought to market, accelerate market adoption of SSL products, and achieve energy savings through use of SSL products. Specifically, they are:

(1) Products Brought to Market: induce the manufacture and purchase of highly efficient LED luminaires and replacement lamps, leading to U.S. market introduction by FY 2016 of warm white LED general illumination products achieving at least:

a. $112 \mathrm{~lm} / \mathrm{W}$ efficacy; 
b. $85 \mathrm{CRI}$ (or similar level for revised color quality metric), and;

c. 2580-3710 K CCT.

For cool white LED general illumination products, at least:

a. $131 \mathrm{~lm} / \mathrm{W}$ efficacy;

b. $75 \mathrm{CRI}$ (or similar level for revised color quality metric), and;

c. $4746-7040 \mathrm{~K} \mathrm{CCT}^{1}$

(2) Energy Savings: influence application of SSL products such that electricity savings of at least 21 TWh per year are achieved by FY16.

The goals of the Market Development Support Plan are linked to the performance targets in the May 2012 DOE SSL R\&D Multi-Year Plan. Achieving the future performance levels described above very much depends on DOE's success in reaching the performance levels described in its R\&D Multi-Year Plan (DOE, 2012).

\section{Desired End State}

DOE can be confident that further market support is unnecessary and can justify conclusion of its SSL market development support efforts when the U.S. market for highperformance SSL products achieves a state DOE believes will be self-sustaining, as defined by the following characteristics:

(1) Products Brought to Market: at least twenty $200+\mathrm{Im} / \mathrm{W}$ (luminaire or replacement lamp efficacy) warm or cool white general illumination products are offered for sale by major manufacturers (and are available in most major markets through normal lighting equipment sales channels), and;

(2) Market Adoption of Products: the above products comprise $15 \%$ of annual luminaire and replacement lamp sales in the U.S., and;

(3) Energy Savings: annual U.S. electricity savings from SSL reaches 122 TWh per year.

\footnotetext{
${ }^{1}$ The efficacies, CRIs, and CCT ranges listed here as goals are consistent with those projected in the 2012 DOE Multi-Year Plan for SSL R\&D. The warm and cool white CCT and CRI numbers are intended to add definition and meaning to the efficacy targets. They are not intended to suggest DOE is only interested in targeting lamps that meet these narrow requirements (DOE, 2012).
} 


\section{Market Barriers Addressed by Plan}

Owing to its technical potential for greatly improved performance and greatly reduced costs, the longer-term barriers to market acceptance faced by SSL technology appear modest. Its nearer-term barriers are primarily a consequence of the technology being in its early stages of technical maturation, and its nascent introduction to the market as a general illumination product. As large private and public R\&D investments steadily yield large improvements in the technology, SSL is expected by most observers to make its way deeply into the general illumination market. Still in question are how long this market penetration will take, and the extent of resulting energy savings. Accordingly, this plan is focused on near-term market barriers and needs.

The primary near-term market barriers faced by SSL general illumination products are:

- High costs relative to competing technologies - SSL is cost effective for many applications and for many users; however, depending on the application, electricity rates, hours of use, and other factors, it is often not cost effective. Despite its improving cost effectiveness, its initial costs remain relatively high compared to conventional light sources, deterring buyers from considering SSL. For example, a good quality LED replacement lamp for a 60W A19 incandescent bulb currently costs about $\$ 40$ to $\$ 50$ per kilolumen, a CFL replacement lamp cost about $\$ 2$ per kilolumen.

- Limited industry standards and test procedures for SSL general illumination products - The SSL industry has made substantial progress in developing new standards and test procedures for the industry. IES LM-79, IES LM-80, ANSI C78377, IES RP-16, UL 8750, NEMA SSL-1, and IES TM-21, among others, have made important contributions to facilitating the adoption of SSL technology. But much remains to be done, ranging from important updates to several of these documents, to new standards for estimating luminaire and lamp life, to characterizing the performance of LED light engines, a full set of standards and test procedures for OLEDs, and many others.

- Lack of information (for buyers, and lighting professionals) - In these early days of LED technology development and adoption there remain widespread information problems. Buyers have difficulty understanding the performance of new products, and in particular, whether selected products are suitable replacements for the conventional light sources they are presently using. Similarly, lighting professionals, while typically holding far more sophisticated understanding of SSL technology, still struggle with a wide range of conflicting information on LED performance characterization and appropriate application. Electric utilities, who spend millions in ratepayer funds promoting more efficient technologies to their customers, still routinely struggle with how and whether to incorporate SSL products into their energy efficiency programs. And last, 
misinformation distributed by perhaps well-intended but misinformed LED product vendors adds to the confusion and unwillingness among buyers to make investments in SSL products. Thus, continuing lack of information and misinformation substantially increases the risk (both perceived and real) of investment in SSL, slowing its market adoption.

- High transaction costs - Given the low familiarity among most buyers and most specifiers with the technology, it generally is much more complicated and time consuming to specify SSL products than conventional products. Many buyers therefore default to lighting products they are familiar with, and to seeking the assistance of professionals whose expertise is primarily with conventional light source technologies, greatly reducing the likelihood they will purchase SSL products.

- Low product quality and performance - While there are many SSL products that perform very well and exhibit high levels of quality, there are also many products that perform poorly, and are likely to fail early. Unfortunately, the latter group very much influences the market reputation for all SSL products, suppressing sales, making specifiers reluctant to specify SSL products, and deterring consumers from trying other SSL products after their first experiences with SSL cause dissatisfaction. The performance issues range from pre-mature failure, to poor color quality, insufficient light quantity, light flicker, poor dimming performance, and rapid lumen depreciation.

Addressing these market barriers with effective strategies can collectively help drive down the costs of SSL by creating near-term market opportunities for SSL, which in turn generates revenue for SSL manufacturers to invest in R\&D and lower-cost production. Further, addressing these market barriers will help build an industry standards/test procedure infrastructure that is widely recognized and used, allowing manufacturers to characterize their products in terms clearly understood by potential buyers. And last, addressing these market barriers helps equip lighting industry professionals, facility operators, lighting specifiers, energy efficiency program sponsors, retailers, and consumers with the information they need to make good purchasing decisions, and to properly apply this new technology.

\section{Market Needs Addressed by Plan}

The plan identifies 10 key SSL market needs for DOE market development support. They are:

1) Effective product purchasing guidance for retailers, facility managers, other large volume buyers, consumers, and other agents that act on their behalf, such as lighting specifiers and electric utilities (to guide buyers to products that are likely to perform well) 
2) Market visibility for high performance, commercially available products (to educate the market about the technical potential of the technology in welldesigned products)

3) Well-documented case studies of SSL general illumination installations (to inform the market about application issues, energy performance and cost effectiveness)

4) Market introduction support from energy efficiency program sponsors (to help SSL manufacturers build sales volume for high performance products, thereby increasing the demand for high performance products and driving down technology costs)

5) Independent performance test results on commercially available products (to counter exaggerated performance claims made by vendors, to encourage manufacturers to use industry standard test procedures as a basis for performance claims, and to provide a high quality dataset on product performance that can be used to analyze trends and product performance issues)

6) Objective, widely available technical information from a credible, respected source (to help fill information gaps and increase understanding of the technology, its attributes, and its limitations)

7) Support for development of industry standards and test procedures for SSL general illumination products (to enable basic market infrastructure)

8) Coordination of local, regional, and federal SSL market development activities (to maximize effect of invested public and ratepayer money)

9) Independent investigations from a credible source of key SSL issues affecting market adoption of SSL (to provide up-to-date information on SSL market development for both DOE and industry planning and analysis purposes)

10) High visibility technology competitions (to spur innovation by reducing the risks of developing and selling very high performance, state-of-the-art, SSL products)

Meeting these market needs can collectively help drive down the costs of SSL by expanding market opportunities for high performance SSL, which in turn generates revenue for SSL manufacturers to invest in R\&D and lower-cost production. Further, meeting these market needs will help build an industry standards/test procedure infrastructure that is widely recognized and used, allowing manufacturers to characterize their products in terms clearly understood by potential buyers. And last, meeting these market needs helps equip lighting industry professionals, facility operators, lighting specifiers, energy efficiency program sponsors, retailers, and consumers with the information they need to make good purchasing decisions, and to properly apply this new technology.

The market needs were used for deciding upon a general strategy, and deciding which types of programs and projects DOE should create, and what general form they should take. 
To overcome the above identified market barriers, to achieve the above five-year goals, and to move the SSL market toward the end state at which DOE involvement is no longer needed, DOE proposes to carry out the following strategy.

DOE will implement a multi-year program to accelerate adoption of good quality, high performance SSL products that achieve significant energy savings and maintain or improve lighting quality. Relying on lessons learned from past emerging technology introductions, such as compact fluorescent lamps, and using newly developed market research, DOE will design its efforts to minimize the likelihood that the SSL market will repeat mistakes that greatly delayed market adoption of earlier emerging technology market introductions. To achieve the maximum effect per dollar invested, DOE will work closely with lighting industry organizations - such as the Next Generation Lighting Industry Alliance, Illuminating Engineering Society of North America, and the International Association of Lighting Designers - and with other government programs seeking to improve lighting energy efficiency. While DOE will work closely with these organizations and others from lighting and electric utility industry, the program will focus primarily on assisting buyers of SSL products and others acting on their behalf because satisfied buyers are essential to the success of SSL market adoption. The work product of DOE's efforts will primarily be information, of the right type, at the right time, and provided efficiently to those who can best use it. A secondary work product of DOE's program will be market opportunities, in which DOE will seek to reduce the risks and costs for manufacturers of SSL products to sell good quality, high performance products to motivated buyers.

In short, DOE plans to implement a multi-year program that produces highly useful and widely available information for buyers and their agents, while producing important market opportunities for producers, avoids the mistakes of the past, and is closely coordinated with industry and government.

\section{Key Program Elements}

To implement this strategy, DOE developed the following key program elements. They were selected on the basis of:

- Consistency with appropriate federal role

- Expected impact on market development

- Expected impact on potential energy savings

- Expected program costs being cost effective and not exceeding available resources 


\section{Multi-Year Plan for SSL Market Development Support}

Goals: By FY 2016, induce market introduction of general illumination SSL warm white products that achieve $112 \mathrm{~lm} / \mathrm{W}$ and cool white products that achieve $131 \mathrm{~lm} / \mathrm{W}$ (luminaire or replacement lamp efficacy), and achieve $21 \mathrm{TWh}$ annual energy savings.

\section{Program Elements}

1) LED Lighting Facts (MNs: $1,4,5$, \& 6)

- LED Lighting Facts

- SSL Quality Advocates

2) Next Generation Luminaires Competition (MNs: 2, 4, \& 10)

3) GATEWAY Technology Demonstrations (MNs: 1, 2, 3, 6, 8 \& 9)

- Demonstrations

- Technology Demonstration Consortia

4) Commercially Available LED Product Testing \& Evaluation Program (CALiPER) (MNs: 1, 5, 6, 7, \& 9)

5) Technical Information

- Technical Information Development and Dissemination

- Technical Information Network

6) Standards and Test Procedures Support (MN: 7)

7) Coordination/Leadership ( $\mathrm{MN}: 8$ )

- Facilitating and Coordinating Local and Regional Efforts

- Federal Government Leadership

8) Market Studies and Technology Evaluations (MNs: $7 \& 9$ )

9) Technology Prize Competitions (L Prize) (MNs: 4, 5, 8 \& 10)

NOTE: The MN numbers refer to the market needs identified in this plan (page 12). The list of numbers after each Program Element identifies the market needs addressed by that particular element.

\section{LED Lighting Facts}

For the solid-state lighting market to grow, buyers must have accurate information that allows them to choose the right products for their applications. The DOE LED Lighting Facts program showcases LED products for general illumination from 
manufacturers who commit to testing products and reporting performance results according to industry standards, and provides information essential to evaluating products and identifying the best options.

Jointly developed by DOE and the Next Generation Lighting Industry Alliance (NGLIA), LED Lighting Facts is a voluntary online pledge program to ensure that LED lighting, as it reaches the market, is represented accurately - whether in product labeling, product packaging, product literature, press releases or manufacturer data sheets. The ultimate goal is to facilitate consumer adoption of this energy-saving technology and avoid some of the missteps that plagued market adoption of CFLs.

Central to the program is the LED Lighting Facts label which presents independently verified performance data in a simple summary that facilitates accurate comparisons between like-products. The data is measured by the industry standard for testing photometric performance, IES LM-79-2008, and currently covers five areas: light output (lumens), watts, efficacy (lumens per watt), correlated color temperature, and color rendering index.

The DOE LED Lighting Facts program is open to all those who manufacture, sell or recommend LED lighting. Manufacturers pledge to test their products and register them with LED Lighting Facts. In conjunction, an array of LED Lighting Facts partners-buyers, contractors, specifiers, designers, retailers, utilities, and energy efficiency programspledge to look for and use products that are registered and listed with the LED Lighting Facts program. By doing so, the program helps them guard against exaggerated and unverified claims by introducing transparency to the lighting supply chain.

\section{a. LED Lighting Facts}

http://www.lightingfacts.com/

The primary objective of the DOE LED Lighting Facts program is to provide credible, verified performance information about LED lighting products to retailers, utilities, specifiers, energy efficiency program sponsors, and lighting users. Since its inception in early 2009, the LED Lighting Facts program is a voluntary program that has become a "go to" resource for buyers and specifiers and a "must have" for manufacturers. As the number of products grows, the value and momentum increases, which has created a groundswell of support that helps the entire industry. In the first two years of the program, DOE's efforts have focused on recruiting manufacturers, retailers, distributors and utility/energy efficiency groups to take the LED Lighting Facts pledge and make the program part of their effort to market, promote and sell quality SSL products. To date, the program has attracted 250 manufacturers, verified the performance of more than 2,880 LED products registered to the program list and label and engaged 195 retailers and distributors who sell LED products, including four of the largest national chains, and another 200 lighting professionals and utility programs who specify and promote products. 
The value of this program continues to be in providing the buyers, including retailers, distributors, designers, and utilities, the ability to evaluate and compare products using verified performance data. The program leverages the largest database of its kind of product performance of LED products to provide resources through the infrastructure of the web-based interface that enable the following:

1) Online and dynamic searchable product database of verified performance levels

2) Ability to compare and screen products based on selected performance criteria

3) Regular reporting and analysis of product performance trends and projections

4) Quality assurance through off-the-shelf testing of registered products to determine consistency with submitted product testing reports, and recognition of products in compliance

5) Additional performance metrics for product comparison and evaluation, such as reliability and warranty.

A key element of the program is a targeted retailer outreach effort designed to help lighting buyers and distributors better understand the SSL market, thereby increasing the potential for successful market adoption. The focus of this effort is to ensure that retailers understand how to evaluate products and identify poor performers by helping them stay informed of evolving product trends, DOE SSL program updates, and program resources that LED Lighting Facts continuously creates and updates. Among the many LED Lighting Facts retailer partners, there are four large retailers who are actively engaged, and the program is actively recruiting other large retailers. The focus on large retailers is to ensure that the program has the largest possible impact on the market.

Going forward, LED Lighting Facts will continue to review aspects of SSL that raise questions and concerns for retailer partners, and will continue to adapt to their everchanging needs with this rapidly evolving technology. The program will provide findings from quality assurance testing, as well as assist retailers with difficult SSL performance questions on issues such as lifetime and directionality. The program will continue to emphasize factual performance information in retailer outreach, because retailers' understanding of the technology and the market directly impacts how they are communicating the benefits of SSL to their customers.

\section{b. SSL Quality Advocates}

www.ssl.energy.gov/advocates.html

Jointly developed by DOE and the Next Generation Lighting Industry Alliance (NGLIA), SSL Quality Advocates is a voluntary pledge program to assure that LED lighting, as it reaches the market, is represented accurately. Encouraging the development of high-quality products that perform as claimed is essential to buyer satisfaction and will help drive market acceptance of solid-state lighting (SSL) products. 
SSL Quality Advocates is composed of members of NGLIA, DOE contractors, and other experts in reliability, lifetime, and LED technology. After creating the LED Lighting Facts label, SSL Quality Advocates began focusing on developing guidance for how manufacturers could characterize the reliability of SSL products. As with the LED Lighting Facts label, the group believed this kind of information was important for maintaining buyer satisfaction with SSL products, and therefore important to the long-term market acceptance of SSL. The group has produced and continues to update a guide on testing and reporting luminaire lifetime (NGLIA \& DOE 2011). The work of the group is now focused on providing guidance to standards bodies through recommendations on lifetime and reliability that support the needs of the SSL community. The standards organizations will ultimately determine the details of the methods to measure and report the reliability of SSL products.

\section{Next Generation Luminaires Design Competition}

http://www.ngldc.org/

The Next Generation Luminaires (NGL) design competition, focused only on SSL luminaires for the commercial specification market, was launched in partnership with Illuminating Engineering Society of North America (IES) and the International Association of Lighting Designers (IALD). The evaluation of products by a respected, non-biased judging panel and independent testing according to LM-79 are major components of the competition. NGL marketing materials highlighting the recognized products are an excellent resource for lighting specifiers seeking quality LED products currently ready for specification.

DOE plans to continue to cooperate in NGL with its partners, focusing its resources on meeting the needs of lighting specifiers in the commercial market. Strategic plans for DOE's role in NGL include:

- expanding activities to include separate indoor and outdoor competitions;

- highlighting luminaire efficacy and potential energy savings, and;

- expanding the competition to include an architectural design component.

To the extent possible, DOE will attempt to link winners of the competitions with other projects, especially within the DOE portfolio. 


\section{GATEWAY Technology Demonstrations}

www.ssl.energy.gov/gatewaydemos.html

Though solid-state lighting is successfully penetrating some components of the market, much unfamiliarity remains among mainstream user groups who have questions about reliability, performance, and cost-effectiveness of LED products. DOE will continue its highly visible GATEWAY demonstration program to: a) continue generating data on the market readiness of the technology, b) contribute to the growing body of field experience and related literature on the use of solid-state lighting, and c) work with large-scale buyer consortia to help address their specific needs with respect to use of LED products. GATEWAY demonstrations span commercial, roadway, industrial, and residential applications, but GATEWAY intends to focus primarily over the next few years on commercial, roadway, and industrial applications because that is where SSL market uptake is gaining most traction, and that is where resulting energy savings are likely to be highest.

\section{a. Demonstrations of Field Performance and Market Readiness}

GATEWAY seeks to work with products whose energy performance is better than the products they are replacing and whose lighting performance meets IES Recommended Practice minimums. Even though many products now present low technical risks to users, many of them still face ongoing market hurdles simply because they are new and unfamiliar. DOE minimizes the risk of unsuccessful demonstrations for project hosts through careful selection of candidate products and appropriate applications to ensure a suitable match, and limits participation to those projects offering high likelihood of success.

In general for these projects, DOE:

- identifies target products/applications/host sites for demonstrations;

- evaluates proposed products to assess their quality and performance, including verification through laboratory testing and lighting simulations;

- works with the user to install products in host facilities;

- measures and evaluates performance in the field; and

- prepares and widely distributes project reports.

GATEWAY will continue to investigate new applications for solid-state lighting as LED performance improves and prices drop, increasing the range of viable applications in the market. GATEWAY will focus its emphasis on applications where there tends to be greater uncertainty concerning market readiness of the technology or particular application. 


\section{b. Contributions to the Body of Field Experience and Literature}

Solid-state lighting products are different in many critical respects from other lighting technologies. From operating characteristics to lifetime to control capabilities and numerous other attributes, LED products yield the greatest success when their individual properties are sufficiently taken into account during design, procurement, and installation. However, users still tend to bring a more traditional-product mindset to LED implementation because that is all they know; the pervasive lack of field experience with LEDs prevents more appropriate consideration in planning and implementation, and this situation will be slow to change on its own. As the period of time LEDs have been installed in the field expands, however, an increasing body of data becomes available for improving the general knowledge of LED use. GATEWAY will strive to continue to disseminate such information as widely as possible via the DOE SSL website, conference presentations, trade industry news media, and other channels.

For example, as of summer, 2011, the longest-running LED products in continual commercial operation are only now reaching the three-year mark, so virtually all lifetime estimates to date are still based on projections. However, many persistent questions about LED lumen maintenance and general reliability can be by now at least partially answered with actual data obtained by retrieving samples from their installed locations and submitting to laboratory testing. Unfortunately, such effort and expense are unlikely to be undertaken by most users or even most manufacturers, at least to the degree where results are shared with the public. GATEWAY will thus pursue efforts to revisit earlier project sites to retrieve sample luminaires and operating histories to provide public data on how they have fared during their operation in the field, including measurements on dirt depreciation.

GATEWAY projects also often venture into new territory when installing products in real-world applications, yielding lessons learned and data that are not widely known. For example, solid-state lighting is an enabling technology for use of control systems in selected applications (e.g., motion detectors in parking lots) that to date have been largely incompatible with traditional lighting products. One frequent result of such new capabilities is that issues arise in the interaction among components that have not been previously encountered, and are thus not generally understood within the user community. Open reporting of such results serves to advance the state of lighting knowledge, both helping improve future product designs and assisting users and government bodies (e.g., standards-setting organizations) avoid critical missteps in LED implementation.

GATEWAY will also investigate other enabling technology issues where use of SSL enables energy savings beyond that achieved by using a more efficient light source. Among the issues GATEWAY may investigate are savings from improved outdoor stray light control, placement of indoor light sources closer to lighting targets, and improved roadway visibility through improved lighting uniformity. 
As a general rule, GATEWAY will strive to produce data and documentations that address questions and uncertainties pertaining to this new technology that present significant barriers to its widespread implementation. Because solid-state lighting is still relatively new to the market, the related opportunities for original investigation are numerous.

c. Work with Large-Scale Buyer Consortia

The number of organizations considering LED lighting has quickly grown as knowledge about its potential benefits has spread throughout the lighting and energy efficiency communities. In general, GATEWAY and the DOE SSL program try to work with large groups of like users to leverage the impact of demonstrations and other efforts.

For example, the DOE SSL program supports the Municipal Solid-State Street Lighting Consortium to assist municipalities and utilities make better-informed decisions regarding the selection and implementation of solid-state street lighting products. The program also assists the Commercial Building Energy Alliances by developing LED lighting specifications for use by all members of the particular subject group. The GATEWAY program facilitates this endeavor by performing evaluations of lighting products and developing trial case studies using the draft performance specifications. In all cases feedback is widely disseminated among the subject groups on what works and what needs additional refinement.

Going forward, DOE will continue working with these consortia and will define new user groups and related new activities as needed. The first new consortium DOE will seek to form will be one that will focus on indoor lighting applications. Discussions are underway as to which subsector of that market is most suitable for this kind of activity. Early indications suggest that municipalities and local governments would be a good early target, given they are already working closely with DOE on outdoor lighting, have enthusiastically sought new information on SSL, and represent a large amount of buying power.

\section{Commercially Available LED Product Evaluation and Reporting (CALiPER)}

www.ssl.energy.gov/caliper.html

DOE conducts an SSL commercial product testing program to serve multiple purposes: 1) encourage high performance of LED products in terms of energy efficiency and lighting quality; 2) support testing labs as needed to help them consistently and accurately test SSL lamps and luminaires; 3 ) provide feedback to industry standards 
organizations; 4) support the LED Lighting Facts quality assurance (QA) program; 5) provide input to the DOE SSL R\&D, Manufacturing, and Commercialization activities; and 6) provide objective information to all interested parties.

The program broadly monitors SSL general illumination products available in the market, and identifies products that are high priority targets for testing, weighing a number of factors intended to serve the three purposes of the program described above. Products are purchased and then tested by one of several contractors arranged to assist this program. Tests include a number of electrical, photometric, and colorimetric measurements. Manufacturers of tested products are given an opportunity to comment on test results prior to their finalization. Testing results, summaries, and interpretations are distributed in both hard copy and via the DOE SSL website.

The testing conducted to date has already revealed important technical issues, including power consumption by LED luminaires in the off state, and the need for better definition and standardized procedures for rating the performance of individual LED packages. Issues identified through the testing program will feed into the standards development process. As SSL product performance becomes more competitive with traditional technologies and the industry understanding of SSL testing and performance matures, the CALiPER program will evolve to meet changing needs.

While CALiPER tests both residential and commercial lighting products, DOE intends to increase its focus on commercial and industrial products because products used in those sectors will likely lead to much larger energy savings sooner than products in the residential sector.

This program will be continued and expanded in the following ways:

- The number of products tested per year will be at least 200, subject to budget constraints, product availability, and program needs.

- The program supports linkages with stakeholder groups for understanding testing best practices, credibility, new developments, improvements (independent testing arena, manufacturers, NVLAP and accreditation community, FTC/NEMA/IES, European and International testing arena, purchasing, acquisitions, and distributors, retailers and specifiers, EEPS and utilities...).

- CALIPER monitors, facilitates and provides expert support for pathways to introducing new testing paradigms (new testing techniques, new scopes, extended scopes of SSL product testing...).

- Information developed in the program will be marketed through promotional efforts, wider distribution of program materials, conference exhibits, and linkages with related lighting and energy efficiency programs. 
- Reports based on analysis of accumulated test results will be periodically prepared to identify important trends and issues needing consideration by DOE and other entities interested in monitoring the performance of commercial SSL products.

- The CALiPER Guidance Committee representing energy efficiency program sponsors (EEPS), utilities, lighting designers, and key industry experts will continue to convene and transition as needed with the SSL market maturation.

- As SSL technology and implementations evolve, the focus of CALiPER testing should evolve to encompass new issues such as componentization, substitutability, process control, and OLEDs.

- CALiPER will be integrated with the LED Lighting Facts program, such that test reports voluntarily submitted to DOE for product listing in LED Lighting Facts will be included in the database of performance information available from the CALiPER website, and used for analysis in CALiPER reports.

- CALiPER will begin to investigate and implement changes to make CALiPER information more easily accessible by the public. This is being done to increase the impact that CALIPER has on SSL market development. In particular, CALIPER will make the test results available on its website more easily accessible by the public.

CALIPER will also expand the number of special investigations it conducts. These investigations are intended to support standards and test procedure development, and help resolve priority technical issues that are holding back the market development of SSL. For example, CALiPER will expand its investigations and measurements conducted during FY11 on luminous flux modulation, or flicker, in solid-state lighting products. This investigation will address interdependent photo(metric)-electrical performance issues, specifically: dimming, flicker, and power quality. Work products will likely include slide presentations, technical papers, contributions to DOE SSL program technical information/education efforts, contributions to industry standard(s) development (including IEEE P1789, future IES LM or NEMA dimming standard), and contributions to commercial testing lab procedures.

The feedback loop that CALiPER testing data provide for the SSL program is an especially important function. Accurate, up-to-date data on actual performance of commercially available products helps DOE establish R\&D, standards development, and technical information program priorities. These test results also help identify product performance issues in need of special attention. In addition, CALiPER helps the overall DOE SSL program by providing testing assistance to GATEWAY, L Prize, Next Generation Luminaires, and by providing key information to standards committees and test laboratories on testing issues encountered, which in turn helps improve standards and test procedures.

Since its inception in 2006, CALiPER has had a "No Commercial Use Policy," which declares that users of CALIPER information may not use this information for commercial 
purposes, such as in advertising to promote one's product or to denigrate a competitor's. DOE implements this policy by publishing reports that refer to products only by their test number, and not their brand names. If users of CALiPER information want access to the on-line individual product reports that identifies brand names for each test, they have to first agree electronically to the No Commercial Use Policy.

The policy was instigated partly to encourage the lighting industry to embrace CALiPER by minimizing the chance that its information would be misused (which so often happens in promotional materials), and to make CALiPER as fair as possible to companies whose products have or have not been tested. Some manufacturers feel disadvantaged by having their products tested, believing DOE is unfairly focusing on their products when so many other companies have products that perform as poorly. And some manufacturers feel disadvantaged by NOT having their products tested, believing they would rank well compared to similar products that have been tested by CALIPER. Since CALiPER cannot test all products in the market, there may be many manufacturers who feel disadvantaged by CALiPER if they believe their products perform well relative to others, and if their customers want to see independent CALiPER-style test information. If this information were usable in commercial materials, DOE believes some manufacturers would feel even more disadvantaged than they feel under the No Commercial Use Policy.

However, some companies and industry observers believe CALiPER information should be made more widely available, and that the No Commercial Use Policy should be retracted. They argue the public would be better served by easier and wider access to CALiPER test results associated with a product name.

In response to these calls for wider and easier access to CALiPER information, DOE will initiate a review of the No Commercial Use Policy in FY13. A wide range of views will be solicited before a decision is made on how to proceed. CALiPER has worked well and has helped shape the SSL industry, so DOE wants to proceed with any changes carefully.

\section{Technical Information}

www.ssl.energy.gov/technetwork.html

\section{a. Technical Information Development and Dissemination}

DOE will continue to implement a multi-faceted technical information effort whose purpose is to inject high-quality, objective, impactful information into the emerging SSL market such that buyers can make better SSL purchasing decisions. Informational material developed for this effort does not target general consumers. Instead, it is 
developed for facility managers, energy managers, lighting professionals (such as designers and specifiers), as well as organizations (such as electric utilities) that develop educational material for residential and commercial buyers. DOE plans a new technical information effort aimed at contractors and electricians who are encountering significant problems in specifying and installing SSL products. DOE will need to work with the National Electrical Contractors Association to reach these professionals.

Technical information to be developed and distributed by DOE will include:

- Explanations of SSL technology and relevant standards (technology primers)

- Product/performance specification guidance

- Buying guidance, including economic performance evaluation tools

- Lighting application/design guidance

- Explanations of light quality, with emphasis on how they can identify SSL products with higher light quality

- Material addressing a range of environmental issues, including the effects of light at night on humans and wildlife, blue light hazard for humans, recyclability, waste minimization, and life cycle analysis of SSL products relative to other light sources

DOE's technical information is posted on the Market Programs section of DOE's SSL Website. These materials serve participants in the Technical Information Network for Solid State Lighting (TINSSL) and others. Materials posted on the Website are regularly updated and expanded, creating a rich, highly useful collection of technical information.

Content pages on the Website will be coordinated with a range of printed technical materials, to minimize overlap (and contradiction). These materials will be primarily in the form of two or four-page PDF fact sheets that can be downloaded for use by Website visitors, and which will be distributed at conferences and meetings. An SSL Program booth developed in FY09 will continue to be used to showcase and share DOE SSL technical information and materials from other market introduction support activities (CALiPER, GATEWAY Demonstrations, Next Generation Luminaires, etc.)

\section{b. Technical Information Network for Solid-State Lighting}

To maximize the effectiveness of this effort, DOE relies heavily upon the Technical Information Network for Solid State Lighting (TINSSL), established to leverage existing outreach programs in key lighting markets. Creation of the network is based upon the idea that it is far more cost-effective and impactful to leverage existing, well-established information channels than to create new ones. Organizations and companies participating in this network include electric utilities, regional market transformation organizations, state energy offices, and other operators of energy efficiency programs. 
The network educates participants about SSL technology and key issues in its effective application, serves as a forum for information sharing by SSL program innovators, and helps identify SSL market and technical issues that require DOE's attention. This is a critical step in development of the market in a way that maximizes energy efficiency and quality. The TINSSL Planning Committee, whose members represent utilities, energy efficiency organizations, and others involved in supporting the early market introduction of SSL produces through incentives and other programmatic support, meet once per month via conference call and periodically at events such as DOE SSL Market Introduction Workshops, and conferences sponsored by TINSSL members. TINSSL PC members provide feedback to DOE on current and new Technical Information materials and help identify topics for National DOE-sponsored SSL Educational events, which TINSSL sponsors four or more times per year.

Activities to be conducted by TINSSL include:

- Monthly telephone conferences among TINSSL PC participants to plan DOE activities, share information on SSL activities among participants, and to review technical information materials developed for participant use;

- Webcasts for TINSSL members on topics of particular interest to energy efficiency program implementers. These events are by invitation only and are smaller than the general SSL events, in order to allow a more focused discussion among program providers and implementers;

- Webcasts on selected SSL technical topics of broad interest, presented by DOE or outside subject matter experts;

- Development of technical educational material that can be branded by TINSSL participants and used throughout their own technical information distribution networks;

- Development and maintenance of technical information on the DOE SSL website;

- Provide direct technical assistance to TINSSL members, such as review and comment on the technical content of proposed SSL energy efficiency programs;

- Assist electric utilities with development of technical materials and specifications for SSL programs. DOE leadership is needed to help establish guidance for product performance based on the unique needs of key SSL applications, and the state of the technology. Applications often coincide with fact sheet topics, and TINSSL members often coordinate with DOE on these specifications to help ensure that the guidance meets the needs of program implementers.

c. Purchasing Guidance

Most facility managers and their consultants are still unfamiliar with SSL technology. Its unique characteristics, flexibility, and appropriate application will take time for facility and lighting professionals to learn. From DOE's perspective, a very important 
element of this learning process will be how to apply this technology in a manner that meets lighting quality needs yet maximizes potential energy savings.

As the technology evolves, the range of applications to which it can be appropriately applied will grow, though use of conventional lighting technologies will continue to be more efficient for a number of lighting applications for some time. Helping facility and lighting professionals and their customers sort through this complicated terrain will increase the likelihood that the U.S. can attain the early energy savings potential of the new technology.

An attractive starting point for DOE efforts to provide purchasing guidance is the Federal sector, where DOE has a lead role in providing technical support to federal agency efforts to reduce energy consumption. An Executive Order announced January 24, 2007 directs federal facilities to reduce energy use by 30 percent by end of FY2015, relative to 2003 levels. $^{2}$ SSL will potentially play an important role in reaching this goal. Initial outreach by DOE to federal agencies has elicited a high level of interest in demonstrating and evaluating SSL technologies. Early federal sector experience in terms of specific product performance, energy savings in specific applications, product costs and procurement issues, and impact on maintenance and lighting service will be captured, synthesized into guidance documents, and shared with the federal sector through the Federal Energy Management Program, the Inter-Agency Energy Task Force, and the Federal Utility Partnership Working Group. DOE will seek to have this information incorporated into government building design guidance, such as the General Service Administration's "Facilities Standards for the Public Buildings Service," GSA P-100.

The guidance documents will be organized by application, for example, task lighting for modular offices, recessed downlighting, or parking area lighting. To be useful to those responsible for selecting lighting technologies for federal facilities (i.e., facility managers, consulting lighting designers, lighting contractors, etc.), the following information is necessary: 1) product performance data based on traceable test procedures and in standard IES photometric file format; 2) cost information, including purchase, installation and service costs; 3 ) information on in-situ performance, such as results of field testing.

As DOE builds a database of performance information on a variety of luminaire types (through CALIPER), and implements demonstrations in various federal and non-federal facilities, DOE will produce a series of LED purchasing guidance documents. This information will be of use and interest not only in the federal sector, but also in the wider lighting design community.

\footnotetext{
${ }^{2}$ http://www.gpo.gov/fdsys/pkg/FR-2007-01-26/pdf/07-374.pdf
} 
The first activity of this type was launched in FY11 in cooperation with the FEMP Program. Its initial focus is outdoor lighting. Guidance is being developed in cooperation with Inter-Agency Energy Task Force. DOE plans to continue this type of activity within the federal sector, seeking out opportunities to provide assistance.

\section{Standards and Test Procedures Support}

www.ssl.energy.gov/standards.html

When DOE initiated its SSL market development support efforts, there were no industry standards or test procedures specifically for SSL general illumination products. Knowing the importance of standards and test procedures for the successful market adoption of the technology, an intensive effort was initiated to organize and support the organizations with responsibilities for developing these standards and test procedures. Much progress has been made since the March 1, 2006 launch of these efforts. As of September of 2011, several key test procedures and standards were complete: IES LM79 (photometric testing), IES LM-80 (lumen depreciation testing), ANSI C78.377 (chromaticity standard), IES TM-21, UL 8750 (safety), NEMA SSL-1, NEMA SSL-6, and IES RP-16 revisions (SSL definitions). Several other high priority standards and test procedures are still in development and several of the new standards already need to be updated. Additional, next-tier standards and test procedures need to be developed as soon as the initial set of high priority ones are complete. In addition, OLED development has progressed to a point where standards and test procedures are needed to support their market adoption.

The primary responsibility for developing these standards and test procedures rests with the industry standards organizations, such as ANSLG, IES, NEMA and UL with input from $\mathrm{CIE}$ and others including industry, but DOE will offer support for the purpose of speeding standards development and enhancing its technical strength and applicability, and will focus on those standards and test procedures needed to achieve SSL's energy saving potential. DOE plans to continue to support these efforts with national meetings, coordination assistance, technical assistance, procedure development and review, and laboratory testing.

A part of the DOE support will be to help identify and prioritize appropriate focus areas for standards and procedure development to support current federal and commercial program needs. This prioritization is based on emerging issues identified through sponsored workshops and interaction with industry. Current areas of focus include:

- Reliability beyond LED module lumen depreciation. Efforts will include standards and methods for driver reliability (life) and other luminaire component reliability. 
- LED dimming function and effect on performance and reliability. Efforts will include further development of dimming effects on LED lamp types and development of a dimming performance test procedure. DOE support may include testing to characterize lamp electrical signatures.

- Exploration of flicker characterization and potential issues. Efforts will include creation of a flicker test method for consistent comparison of flicker characteristics between lamps.

- Identification of initial OLED related standards and methods for development. Initial efforts likely to involve test methods for light output and electrical characteristics, product (light and material) degradation and reliability, and color categorization.

- Light quality. From color maintenance, to glare, color quality characterization, and color consistency, light quality remains an important issue affecting the market acceptance of SSL.

In addition, DOE will develop and regularly update a list of SSL related standards that are under development, their status, and the committee/organization leading the effort. This list will be made available on the DOE website to make it easy to access for those needing to track SSL standards development, including smaller companies that are not able to participate in large numbers of standards development committees.

\section{Coordination/Leadership}

\section{a. Facilitating and Coordinating Local and Regional Efforts}

A large number of electric utilities, state energy offices, state RD\&D organizations, and regional energy efficiency programs operate programs to promote the deployment of emerging energy-efficient technologies. The cumulative program resources available to these organizations greatly exceed those of DOE. However, most of these organizations have not yet developed programs that address SSL. DOE could help catalyze activity among these organizations, first by providing much needed technical information on the technology (which is proposed as part of the SSL Technical Information Network), but also by proposing joint projects, providing opportunities for collaboration, and by convening meetings and conferences.

One of the means through which DOE will achieve this coordination is through annual SSL Market Introduction workshops, conducted in cooperation with local and regional organizations. To date, DOE has held six such workshops. These workshops bring together a wide variety of key players in the SSL market, from manufacturers, to electric utilities, regional energy efficiency organizations, lighting designers and specifiers, state and local government officials, facility managers, retailers, and many 
others. The workshops provide a highly valuable way for DOE to stay in touch with the market, and to learn information that it uses to adjust its plans and priorities over time. DOE plans to continue annual workshops, each time coordinating with local organizations implementing SSL programs.

In addition to these national workshops, DOE will work with regional organizations to organize regional workshops on special topics. Topics and workshop locations will be selected to maximize value to regional participants, and minimize difficulty and cost of participation by the target audience.

\section{b. Federal Government Leadership}

A key means by which DOE can provide leadership and catalyze activity in other government funded programs is to stimulate SSL adoption within the federal sector. The DOE SSL program needs to work closely with DOE's Federal Energy Management Program (FEMP), General Services Administration (GSA), and many others for this to be achieved. DOE has already worked closely with programs and agencies in recent years, and plans to continue a wide range of efforts to establish SSL within the federal sector. These efforts includes collaboration on demonstration projects, educational seminars, presentations at meetings and conferences, development and distribution of technical materials designed specifically for the federal sector, technical assistance for model projects, and many others.

Table 1 below lists the federal, non-federal, and international organizations DOE presently works with on SSL. Where opportunities arise, and resources allow, DOE will expand this range of collaboration over the coming years.

Table 1: DOE SSL Program Collaboration with Other DOE, Federal, Non-Federal, and International Organizations

\begin{tabular}{|c|c|c|c|c|}
\hline & Other DOE & Other Federal & Non-Federal & International \\
\hline GATEWAY & $\begin{array}{l}\text {-FEMP } \\
\text {-Commercial } \\
\text { Building } \\
\text { Energy } \\
\text { Alliance }\end{array}$ & $\begin{array}{l}\text {-GSA } \\
\text {-National Park } \\
\text { Service } \\
\text {-Smithsonian } \\
\text {-Dept. of Labor } \\
\text {-Army } \\
\text {-Navy } \\
\text {-Bonneville Power } \\
\text { Administration }\end{array}$ & $\begin{array}{l}\text {-New York State } \\
\text { Energy Research and } \\
\text { Development Agency } \\
\text {-Municipalities (100+) }\end{array}$ & $\begin{array}{l}\text {-Asia Pacific } \\
\text { Economic } \\
\text { Cooperation }\end{array}$ \\
\hline
\end{tabular}




\begin{tabular}{|c|c|c|c|c|}
\hline $\begin{array}{l}\text { CALiPER } \\
\text { Standards }\end{array}$ & $\begin{array}{l}\text {-Building } \\
\text { America } \\
\text {-Commercial } \\
\text { Building } \\
\text { Energy } \\
\text { Alliance }\end{array}$ & $\begin{array}{l}\text {-National Institute of } \\
\text { Standards and } \\
\text { Technology } \\
\text {-National Voluntary } \\
\text { Laboratory } \\
\text { Accreditation Progrm } \\
\text {-EPA ENERGY STAR } \\
\text { - Federal Trade } \\
\text { Commission }\end{array}$ & $\begin{array}{l}\text {-Independent testing } \\
\text { laboratories } \\
\text {-Illuminating } \\
\text { Engineering Society } \\
\text { (IES) } \\
\text {-American National } \\
\text { Standards Institute } \\
\text {-National Electrical } \\
\text { Manufacturers Assoc } \\
\text {-Utilities } \\
\text {-UL }\end{array}$ & $\begin{array}{l}\text {-International } \\
\text { Laboratory } \\
\text { Accreditation } \\
\text { Cooperation } \\
\text {-International } \\
\text { Lighting } \\
\text { Commission } \\
\text {-Institute of } \\
\text { Electrical and } \\
\text { Electronics } \\
\text { Engineers }\end{array}$ \\
\hline $\begin{array}{l}\text { Next } \\
\text { Generation } \\
\text { Luminaires }\end{array}$ & & & $\begin{array}{l}\text {-Illuminating } \\
\text { Engineering Society } \\
\text {-International Assoc } \\
\text { of Lighting Designers }\end{array}$ & \\
\hline L Prize & & $\begin{array}{l}\text {-FEMP } \\
\text {-GSA } \\
\text {-Dept. of } \\
\text { Transportation } \\
\text {-Office of Science \& } \\
\text { Technology Policy }\end{array}$ & $\begin{array}{l}\text {-31 utility and energy } \\
\text { efficiency partners }\end{array}$ & $\begin{array}{l}\text {-European } \\
\text { Commission }\end{array}$ \\
\hline $\begin{array}{l}\text { Planning, } \\
\text { Analysis }\end{array}$ & $\begin{array}{l}\text {-BT Regula- } \\
\text { tory } \\
\text { Program }\end{array}$ & & $\begin{array}{l}\text {-Next Generation } \\
\text { Lighting Industry } \\
\text { Alliance }\end{array}$ & $\begin{array}{l}\text {-APEC } \\
\text { - International } \\
\text { Energy Agency }\end{array}$ \\
\hline $\begin{array}{l}\text { TINSSL/Tech } \\
\text { Info }\end{array}$ & $\begin{array}{l}\text { - CBEA } \\
\text {-FEMP }\end{array}$ & & $\begin{array}{l}\text {-Utilities and energy } \\
\text { efficiency } \\
\text { organizations } \\
\text {-IES }\end{array}$ & \\
\hline
\end{tabular}

\section{Market Studies and Technology Evaluations}

www.ssl.energy.gov/publications.html

To support the above strategies, DOE has completed a number of market studies and technology evaluations. These studies will help guide and shape DOE's strategic decisions, and will help inform individual activities. The first study done for this purpose was, "Compact Fluorescent Lighting in America: Lessons Learned on the Way to Market." (DOE, 2006) That study sought to identify lessons learned from the market introduction experience of CFLs, hoping those lessons would be helpful in shaping the market introduction of SSL products. DOE also updated its report entitled, "Energy Savings Estimates of Light Emitting Diodes in Niche Lighting Applications," in 2011, which presents research findings for twelve niche markets where LEDs are competing or 
are poised to compete with traditional light sources, such as incandescent, halogen, fluorescent, neon, and high-intensity discharge (DOE, 2011). In 2012 DOE updated its Lighting Market Characterization report to provide up-to-date information on how lighting is used in the U.S. by application, light source technology, and other factors (DOE, 2012c). DOE will identify needed studies and evaluations during the course of its program activities. Near-term needs identified thus far include:

- an investigation of the early market adoption of SSL products, with a focus on identifying what is going right, and what is going wrong, providing information useful for making adjustments to DOE's program;

- a study to identify the highest value early general illumination applications for organic LEDs (OLEDs), including identification of key market needs for OLED market introduction;

- a study of alternative approaches for incorporating SSL into the LEED certification program operated by the U.S. Green Building Council;

- a forecast of potential U.S. energy savings from SSL used in general illumination applications;

- a life cycle analysis of SSL technology as compared to competing lighting technologies, with particular attention to environmental releases of toxic substances (such as mercury) during product manufacture and final consumer product disposal, and;

- a study of the cost-effectiveness of SSL for specific lighting applications, relative to competing lighting technologies;

- occasional market surveys in which buyers, vendors, specifiers and others are queried about important SSL market development issues?

- an investigation of the OLED market, with emphasis on how it is different from the LED market, the findings of which will help DOE develop its first OLED market introduction programs.

\section{Prize}

http://www.lightingprize.org/requirements.stm

The Bright Tomorrow Lighting Prize ( $L$ Prize ${ }^{\mathrm{TM}}$ ) was established by Congress in the Energy Independence and Security Act of 2007. The legislation directs the Department of Energy (DOE) to award a total of $\$ 20$ million in prize money to the first manufacturers able to produce solid state lighting products with the following general characteristics:

\section{0-Watt Incandescent Replacement Lamp}

- More than $90 \mathrm{~lm} / \mathrm{W}$ luminous efficacy

- Less than 10 Watts 
- More than 900 lumens

\section{PAR-38 Halogen Replacement Lamp}

- More than $123 \mathrm{~lm} / \mathrm{W}$ luminous efficacy

- Less than 11 Watts

- More than 1,350 lumens

\section{$21^{\text {st }}$ Century Lamp}

- More than $150 \mathrm{~lm} / \mathrm{W}$ luminous efficacy

- More than 1,200 lumens

All products are required to have minimum color rendering index (CRI) of 90 and 25,000 hour life.

Continued rapid advancement in LED technology for general lighting presents the potential for significant electric demand reduction and energy savings, beyond what is possible using today's available consumer lighting products. Currently available compact fluorescent lamps (CFLs) have quadruple the luminous efficacy of incandescent lamps. Yet, for a variety of reasons, CFLs have achieved only about $20 \%$ of the general lighting service (GLS) lamp market nationwide. Although fluorescent and high-intensity discharge (HID) are the dominant light sources in commercial settings, incandescent lamps remain common in hotels, restaurants, small businesses, and institutional/government buildings; as well as in applications such as display lighting, portables, and downlights. Incandescent remains the workhorse of residential lighting, valued for its low purchase price, high light output, good color quality, dimmability, reliability, and variety of wattages, sizes, and beam characteristics. The proliferation of downlights in new residential construction has also created a new growth area for incandescent lamps.

Within the next several years, white light LED products are expected to achieve efficacy twice that of CFLs. LEDs will address some drawbacks of CFLs, such as slow runup time, resilience when switched on and off frequently, and low performance for directional light sources, but will have their own limitations and challenges associated with emerging technologies. Price is likely to be a major one in the near term.

The first L Prize competition was announced in May 2008, following a nine-month program development process led by DOE with intensive collaboration and input from four California-based utilities with extensive lighting energy efficiency program experience and expertise. The resulting program design placed energy efficiency front and center, without sacrificing lighting quality or consumer satisfaction. The May 2008 program announcement included the first two lamp categories identified in the EISA 2007 legislation: the $60 \mathrm{~W}$ incandescent replacement lamp and the PAR38 halogen replacement lamp.

DOE declared Philips Lighting North America the winner of the 60W replacement 
lamp competition in August, 2011. Philips established a production facility near Milwaukee, WI to produce the winning lamps. DOE re-opened the PAR38 competition in March of 2012 after a year-long hiatus during which the competition guidelines were revised and updated based on lessons learned from the $60 \mathrm{~W}$ competition.

The rigorous testing and evaluation process established by L Prize can take up to a year, or more, depending on the entry and on the requirements for the particular competition category. Products selected for award in the competition are likely to enjoy widespread support by energy efficiency programs and demand by large-volume purchasers, including the federal government.

The L Prize strategy encompasses several key elements:

- Aggressive performance targets for participating products, ensuring that winning products will save energy and meet user expectations for lighting quality.

- Nationwide partnerships with utilities and energy efficiency programs representing tens of millions of consumers and market introduction support with incentive and promotion dollars.

- Partnership with the key federal agencies responsible for lighting procurement for federal facilities nationwide and internationally, including the General Services Administration and the Defense Logistics Agency, as well as the Federal Energy Management Program.

- Extensive product performance evaluation including independently-verified photometric measurement, long-term lumen maintenance testing under elevated temperature conditions, stress testing to verify product durability, and field assessments conducted by L Prize Partners nationwide to evaluate installed performance and build familiarity with the products.

- Active publicity and communications efforts for the duration of the program, to ensure interest and motivation by lighting manufacturers, success in recruiting new energy efficiency partners, lasting commitment and engagement by partners, extensive recognition for winning products and their manufacturers, and a high level of interest and demand for winning products by consumers and large volume lighting users.

DOE plans to launch the $21^{\text {st }}$ Century Lamp competition at a date still to be determined. In addition to the competition categories established by legislation, DOE plans creation of additional competition categories. The new categories have not yet been determined, but will be established as budgets allow, as existing categories are closed out, and as opportunities for helping develop the SSL market with this approach present themselves. 


\section{Key Issues to be Addressed in Project Development}

The nine Key Program Elements described in this plan will be used to guide development of projects over the next five years, some of which will be short-term, others may last the entire five-year life of this plan. This section identifies a number of high priority issues DOE plans to consider when developing these projects.

1. Early, low-performing SSL products are likely to cause substantial and lasting market damage. (First impressions are important.)

As occurred with compact fluorescent lamps and described in the report, Compact Fluorescent Lighting in America: Lessons Learned on the Way to Market, early generation, new technology lighting products can cause long-term market damage (DOE, 2006). Disappointed buyers of those early products are reluctant to try the new technology again, even if it has been improved, and share their disappointment with other potential buyers, both of which can lead to long-term market damage.

\section{High costs}

High quality, high brightness LEDs typically sell at a substantial price premium over conventional lighting products on a first cost basis. DOE projects this difference will continue to decline rapidly, but will remain higher than conventional lighting for many years to come. DOE will investigate the cost effectiveness of SSL relative to conventional sources in field studies and hypothetical comparisons, and will also develop tools that help lighting buyers evaluate the cost effectiveness of SSL products vs. other light sources.

\section{LED Color Quality}

The primary tool available to the lighting industry for evaluating the color quality of a light source is the Color Rendering Index (CRI). However research has demonstrated that CRI is an unreliable predictor of color preference, and is biased against some LED sources that render saturated colors well. In response, the National Institute of Standards and Technology is working on development of an alternate means of characterizing color rendering properties, called the Color Quality Scale (CQS). CQS is partly based on color preferences, and partly removes the bias against some LED sources. DOE will monitor these and related developments, seeking opportunities to improve the way in which light color quality is characterized. Until a new color quality metric is accepted by the $\mathrm{CIE}, \mathrm{DOE}$ will emphasize the importance of using R9 values to supplement $\mathrm{CRI}(\mathrm{Ra})$ information for lighting applications where color quality is important. 


\section{Commercial vs. residential luminaire emphasis}

As indicated in the Purpose, Goals, and End State sections, DOE plans to focus on those SSL applications likely to produce significant energy savings. This raises the question of whether to focus efforts on the residential or commercial sector. While commercial lighting dominates U.S. lighting energy use, and thereby represents a much larger potential energy savings target, residential lighting nonetheless represents a significant energy saving opportunity for SSL because incandescent lighting is the dominant light source in the sector, a very inefficient source relative to fluorescent and SSL technology, and because federal legislation requires manufacturers to improve the efficiency of medium base general service lamps (predominantly used in the residential sector).

However, the commercial/industrial market remains the leading candidate for SSL products because:

- electricity costs are generally higher than in the residential sector, and lighting hours of operation are much longer, making the economics of SSL more compelling;

- commercial customers tend to be more sophisticated lighting buyers, and pay more attention to cost-effective lighting investments;

- labor costs for replacement and maintenance are often monetized, making LED durability and long life more attractive, and;

- commercial customers are generally more receptive to lighting products with higher first costs than other alternatives.

DOE will closely monitor changing economics for both commercial and residential applications, as well as changes in the technology affecting SSL's suitability for various applications, but over the next five-year period, DOE plans to focus more of its efforts on commercial/industrial sector lighting

\section{LED Glare}

One of the key advantages of LEDs is the inherently directional nature of their light emissions. Fixtures using LEDs often avoid or limit the use of reflective optics or diffusers that contribute to light losses within fixtures, resulting in high luminaire efficacy relative to fixtures that use diffuse light sources. However, fixtures for some lighting applications that take full advantage of this attribute can also cause significant glare problems. If LED luminaires gain a reputation as unacceptably glary, their market acceptance could be greatly slowed.

At present there is no widely recognized method of glare measurement, leaving glare to be subjectively evaluated by lighting professionals. In the development of its projects and work plans, DOE will be mindful of potential glare issues resulting from poor luminaire designed. In addition, it will work with the lighting industry to improve 
understanding of glare measurement, and possibly support development of objective glare measurements that help LED luminaires steer clear of gaining a reputation for causing glare problems.

\section{SSL as an Enabling Technology}

In addition to the energy savings that can be achieved through use of more efficient LED light sources, SSL enables use of other technologies and practices that can reduce energy use. Numerous examples exist:

- LEDs seem well-suited for frequent switching and dimming in that their lifetimes and lumen maintenance are not damaged by controls that demand many on-off cycles or dimmed states, making many lighting control schemes possible where conventional light sources were not similarly well-suited. To what extent does SSL enable better and wider use of controls?

- LEDs can be packaged in small form factors and can be powered by low-voltage circuits, making it possible to locate LED sources close to light targets, thereby minimizing light spill and losses due to the inverse square law for light. To what extent does placing light sources closer to light targets reduce energy use?

- The superior optical control that can be achieved with small point sources of light, such as from LEDs, enables better uniformity of illuminance and luminance, making it possible to minimize over lighting near light sources while increasing lighting in areas farther from light sources. To what extent does improved uniformity enabled by LEDs improve roadway visibility?

DOE will investigate issues that arise with integrating controls into SSL luminaires, particularly in GATEWAY projects, and in the Municipal Solid-State Street Lighting Consortium. DOE will help the Consortium develop model specifications for SSL controls. Recognizing that lighting controls have the potential to greatly increase the energy savings that can be achieved with the use of SSL, and that among light source technologies, SSL is especially well suited for controls, DOE will seek out opportunities to increase understanding, ease of use, and performance of controlled SSL systems.

\section{Light Loss Factors}

A consensus does not exist on how to characterize light loss factors into lighting designs using SSL sources. Standard luminaire dirt depreciation factors do not exist, nor is there a consensus for how to adjust for projected lamp lumen depreciation. Ambient

and operating temperature effects can vary widely. More effort is needed to investigate these issues so that lighting designers can improve their designs and comparisons with conventional sources. This work needs to be closely coordinated with the IES. 


\section{Dimming Measurement and Performance}

While LEDs are inherently easy and to dim, the promise remains far from reality. Dimming performance remains a major issue slowing the market uptake of SSL, especially when SSL sources are connected to residential two-wire dimmers and when they are connected to low voltage transformers. Observed problems range from visible flicker, to non-visible but potentially harmful flicker, to early failure, to early load drop out. NEMA has made important progress in developing a dimming white paper and a dimming standard for manufacturers, but much more is needed to support the market adoption of products that perform well on dimming circuits. First and foremost, a method to measure and characterize dimming performance is needed. Other important efforts can then follow, such as model dimming performance specifications.

\section{Modularity and Replaceability}

An increasing number of light source modules are appearing in the market, all of them proprietary. The rapid growth in the variety of modules and light source form factors reflect healthy competition in the industry that is helping drive down light source costs, and improve lighting component replaceability. Yet much remains to be done because the dizzying array of light source modules, light engines, and drivers leave buyers wanting. They don't know whether replacement modules will be available for a particular luminaire years after they purchase the product, and they want to have more than one choice for a supplier. While it would be ill-advised to push for standardization of these modules at this stage of the technology's development, DOE will monitor this issue closely, looking for opportunities to help reduce risks of new product purchase to buyers while not inhibiting innovation.

\section{Product Reliability}

Surprisingly to many, the true reliability and lifetime of light-emitting diode (LED) lighting systems is generally not known. Even worse, lumen maintenance values of LED devices are widely used as a proxy for the lifetime of an LED lighting system, which is misleading since lumen maintenance is but one component of a luminaire's reliability. In fact, quite often the lifetime of a well-designed and manufactured luminaire is not determined by LED lumen depreciation. For many manufacturers estimating the luminaire lifetime using LED lumen maintenance, results can be ascribed to dependence on readily available numbers without developing actual luminaire data. In many cases, neither product providers nor customers are aware of the differences, perhaps in part because the problem has not been sufficiently explored and communicated.

It isn't just about the LED. Good LEDs can be incorporated into poorly engineered products and turn the Methuselah of lighting into the exponent of "live fast, die young." The promise of LED lifetime is often presented in terms of hours and years but with little background data. Warranties as well may be misstated because of this lack of data, at 
the manufacturer's peril. The statement "100,000 hours of LED luminaire lifetime" is gradually giving way to the realization that there is little consistency, very little published data, and few hard facts around so-called luminaire lifetime numbers. The situation is better at the LED package level, where reputable manufacturers have thousands of hours of data under varying conditions. But this is not enough.

To manufacturers and specifiers in the SSL world, the dawning realization is that we need to work together toward understanding the issues surrounding true lifetime and reliability. We need to begin by cataloguing failures and developing good models for underlying failure mechanisms. This process of understanding and explanation is very common in technological progress - steam engines existed long before deep comprehension of thermodynamic processes. With LEDs, we have a substantial head start on the underlying physics, many years of experience in both lighting and semiconductors, and reliability of related products.

DOE is making a substantial effort to improve our understanding of SSL product lifetime and reliability, led by a joint DOE/Next Generation Lighting Industry Alliance working group http://www1.eere.energy.gov/buildings/ssl/advocates.html. The documents and additional understanding being developed by this working group are being used to inform decisions being made in the administration of LED Lighting Facts, Technical Information, CALiPER, and many other program elements. While much progress has been made, much more needs to be done to develop a common way of reporting and understanding SSL product lifetimes. This kind of information will increase buyer confidence in the technology, and ultimately, increase the number of SSL products they purchase.

\section{Integral LED Replacement Lamps}

Even though DOE will concentrate its efforts on commercial luminaires for previously described reasons, DOE plans to continue special efforts aimed at integral LED replacement lamps. As federal and California laws phase out inefficient lamps over time, buyers need good alternatives to the inefficient lamps they've been buying. Compact fluorescent lamps are suitable replacements for many of those lamps, but not all. Where higher light quality, better dimming performance, longer life, or more focused light beams are needed, integral LED lamps are often an attractive alternative. DOE will continue to support the integral LED lamp market for consumers with LED Lighting Facts, CALiPER, GATEWAY, L Prize, Technical Information, conference presentations, and other means.

In particular, DOE will make a concerted effort via L Prize, which completed a competition in 2011 for an LED replacement lamp suitable for replacing $60 \mathrm{~W}$ bulbs. As of 2012 L Prize launched a new competition focused on LED replacement lamps for PAR38 halogen lamps. The very high performance replacement lamps that win L Prize competitions help lead and pull the markets for the products to higher performance 
levels, ultimately making LED replacement lamps in these markets a better, more cost effective choice for consumers.

In addition, DOE will emphasize replacement lamp activities in its LED Lighting Facts program, which works closely with retailers, to make information and tools available to retailers to help them make better purchasing decisions on LED replacement lamps. These retailers have been highly responsive to information provided by DOE to date, steadily improving the quality and accurate performance characterization of the LED replacement lamps they carry.

\section{Program Communications}

DOE's SSL overall communications goal is to fully leverage DOE's position as the goto source of credible SSL information to further boost energy efficiency, and to accelerate market adoption of high-quality SSL solutions. More specifically, DOE seeks to increase knowledge about the technology's characteristics, appropriate application, and energy and economic performance in order to maximize national energy savings. The target audiences are described below.

- Supply Side of Market: Corporate executives and managers at SSL manufacturing companies (VPs, product development, marketing, product line management)

- Demand Side of Market: Lighting specifiers and designers; architects and engineers; standards organizations

- Partners/Major Enablers: Utilities and energy efficiency program organizations (EEPs); Federal Energy Management Program (FEMP), DOE Better Buildings/Commercial Building Energy Alliances; General Services Administration, Dept. of Housing and Urban Development, military, and other federal purchasers, State Energy Offices, state and local government purchasers; Large commercial purchasers (building sectors such as hotels and retail chains; facility managers; building owners and operators); Policymakers (State, Federal)

To reach these audiences, DOE plans the following communication goals:

- Ensure that potential buyers know where to go for accurate and clearly understandable performance information

- Recognize and publicize excellence in the SSL field

- Assist lighting designers in rapidly mastering the SSL learning curve, reducing time and risk of specifying

- Provide targeted guidance to large-volume purchasers (government, institutional) to facilitate informed buying decisions 
- Guide utilities and EEPs in structuring incentives for effective market introduction of well-qualified products

In pursuing these goals, DOE's desired outcome is to facilitate informed buying decisions that satisfy customers, aid market success, and maximize energy savings.

DOE uses a number of communication vehicles to reach these audiences. Current vehicles that DOE plans to continue to use include:

- SSL Market Introduction Workshop

- Outreach to lighting professional associations (IALD, IES, NGLIA) and representation in their journals, meetings, e-news, and blogs

- E-news and media materials for program-specific audiences (e.g., Lighting Facts, L Prize newsletter, Consortium Director news)

- Education efforts, via DOE presentations at a wide range of industry conferences (approximately 30 per year)

- SSL Postings (45 per year)

- SSL Updates (60 per year)

- SSL Website

- Webinars (10 per year)

- EERE Progress Reports and press releases

- White papers

- Program Overview Brochure (updated annually)

- Exhibits at LIGHTFAIR and about seven other events and conferences per year

- Articles in professional and trade publications (about 16 columns per year)

- Videos (2 per year)

To build on these existing vehicles and further increase the spread of DOE information, reports, and analysis, DOE plans to implement a number of new vehicles and expanded activities. In some cases the new or expanded vehicles are intended to replicate the success of an existing vehicle with a new target audience. In other cases, the new vehicle is designed to increase the spread of an existing vehicle by delivering a shorter, simpler, more visual, or more interactive version. Examples are provided below.

- Doubling annual webinars, to include both broad topics for large audiences and targeted topics for specific audiences

- Cultivate trade, industry, and professional organizations and publications to increase outreach to their members and readers (e.g., replicate strong media relationships with new target groups such as the municipal organizations and publications) 
- Develop/expand quick-hit updates for dissemination through niche-specific newsletters (e.g., Lighting Facts, L Prize, and possibly others) and other channels

- Create a quarterly e-news on the topic of effective incentive and other market transformation programs

- Repurpose content from meetings, reports, and webinars to extend reach to new audiences through one-pagers (e.g., L Prize and GATEWAY case studies) and/or short targeted alerts

- Expand video strategy to include more informational videos (e.g., L Prize Testing) and/or instructional videos (e.g., Consortium Financial Tool How-To)

- Explore social media strategies that align with DOE policies, particularly related to meetings, conferences, and publications (e.g., Facebook pages for Consortium or workshops, Twitter campaigns for events, etc.)

\section{Partnerships}

In order to reach the audiences described above, DOE plans to cultivate market transformation partners who share DOE's interest in the energy efficiency benefits of SSL and are willing to invest their resources in education and outreach, demonstrations, incentive programs, and other market introduction efforts. These partners will be essential to increasing the reach of the new vehicles and expanded activities described above. Specifically, DOE plans to work with:

- $\quad$ NGLIA: Provides input to shape research priorities and planning for DOE market development support activities.

- IES: Collaborates on development of appropriate standards and guides to assist the lighting community.

- IALD: Collaborates on DOE market development support efforts to improve lighting quality and energy efficiency, with a focus on specifiability.

- American Lighting Association: Its members play a key role in educating the buying public about lighting buying decisions.

- TINSSL: Increases awareness of SSL technology, performance, and appropriate applications.

- Demonstration partners: Showcase high-performance LED products, promote results

- Utility partners: Develop programs and incentives to accelerate market introduction of high-quality, energy-efficient, cost-effective LED products.

These partner organizations provide access to additional buyers and specifiers who may not be familiar with DOE resources. In addition to the above organizations, DOE plans to work with government purchasers and their associations, seeking to use their 
communication vehicles to reach a broader audience. In particular, DOE will pursue working relationships with:

- National Association of State Energy Officers

- International City Manager Association (ICMA)

- U.S. Conference of Mayors

- National League of Cities

- National Civic League

- National Association of Counties

- Council of State Governments

- National Conference of State Legislatures

- National Governors Association

- Members of the Municipal Street Lighting Consortium

The same approach will be applied for additional target audiences as needs develop.

\section{Performance Measurement}

Progress towards the goals of this plan will be assessed using a set of quantitative and qualitative metrics. Results from these measurements will be used to update and modify the plan, improving the quality and effectiveness of its activities. These measures will also be used to facilitate early identification of problems so that timely corrections can be made while any issues are still minor.

The details of the methodology to be used will be developed in FY13 in consultation with experts in market transformation program evaluation. The performance metrics to be used and information collected are likely to include:

1) Identification and documentation of top-performing general illumination commercialized SSL products

2) Annual sales estimates of SSL products

3) Annual energy savings achieved (calculated as the difference between energy savings due to a "natural rate" of SSL market adoption and energy savings due to an accelerated rate of market adoption ${ }^{3}$ )

${ }^{3}$ The "natural rate" of SSL market adoption would occur in the absence of a DOE SSL program. It is not directly measurable, or easily estimated because DOE has already made years of substantial investments in SSL technology development, thus already affecting the rate at which SSL general illumination products are being developed and sold. Based on findings from a National Research Council evaluation of DOE energy research, DOE is estimating its investment in SSL is accelerating the market adoption of the technology by five years. The natural and accelerated market adoption curves are 
In addition to the above performance measurement, DOE will occasionally survey lighting buyers, retailers, and lighting professionals with questions that will help DOE gauge the effectiveness of its education efforts, as well as surveying manufacturers and vendors to gauge the effectiveness of its efforts to help develop the SSL market.

\section{Milestones and Outcomes}

A schedule of key milestones and outcomes, by task, by fiscal year is attached as Attachment A.

\section{Partnerships}

DOE has identified the following key partners whose cooperation will be important to successful implementation of this plan. The resources, expertise, and networks these program partners bring to the efforts represented by this plan greatly multiply any market development DOE can achieve on its own.

In addition to many special purpose meetings that will be held with these partners, DOE often attends meetings and conferences sponsored by these organizations and programs.

\section{Key Partners (not listed in order of priority)}

1) Federal Energy Management Program

2) Energy Efficiency Program Sponsors (utilities, energy efficiency organizations, and state agencies)

3) DOE/BT Commercial Building Energy Alliances

4) U.S. Green Building Council

5) Next Generation Lighting Industry Alliance

6) Illuminating Engineering Society of North America

7) American Lighting Association

8) International Association of Lighting Designers

9) National Association of Lighting Distributors

10) National Electric Manufacturers Association

11) American National Standards Institute

parallel, but offset by five years. The accelerated rate market adoption curve is deemed to be that curve estimated in a recent DOE energy savings estimate (NRC, 2010). The natural rate adoption curve is deemed to be the accelerated curve, plus five years. 
12) Underwriters, Inc. Laboratories (UL)

13) Federal Trade Commission

14) National Institute of Standards and Technology

15) Commission Internationale de L'Eclairage (CIE)

16) Institute of Electrical and Electronics Engineers (IEEE)

17) U.S. Department of Defense

18) General Services Administration

19) L Prize Partners (a growing list of utilities and efficiency programs supporting the L Prize Program (http://www.lightingprize.org/partners.stm)

20) International Energy Agency, 4E Annex

21) LED Lighting Facts Partners

22) Laboratory Accreditation Cooperation

23) European Commission

24) Asia Pacific Economic Cooperation

25) National Association of Electrical Distributors

26) National Electrical Contractors Association

27) Design Lights Consortium 


\begin{tabular}{|c|c|c|c|c|c|}
\hline \multicolumn{6}{|c|}{ KEY MILESTONES AND OUTCOMES } \\
\hline \multirow[t]{2}{*}{ Program Element } & & & & & \\
\hline & FY '12 & FY '13 & FY '14 & FY '15 & FY '16 \\
\hline \multicolumn{6}{|l|}{ Lighting Facts } \\
\hline Lighting Facts & 1500 New Products & 50 New Retailers & 1500 Listed Produts & 50 New Retailers & 1500 New Products \\
\hline SSL Quality Advocates & 1 Major Guidance Doc & 1 Major Guidance Doc & 1 Major Guidance Doc & 1 Major Guidance Doc & 1 Major Guidance Doc \\
\hline \multicolumn{6}{|l|}{ Next Generation Luminaires Competition } \\
\hline Next Generation Luminaires & 12 Comp Winners & 13 Comp Winners & 14 Comp Winners & 15 Comp Winners & 16 Comp Winners \\
\hline \multicolumn{6}{|l|}{ GATEWAY Demonstration } \\
\hline Technology Demonstrations & 8-10 Demos & 8-10 Demos & 8-10 Demos & 8-10 Demos & 8-10 Demos \\
\hline Demonstration Consortia & 2 Major Projects & 2 Major Projects & 2 Major Projects & 2 Major Projects & 2 Major Projects \\
\hline \multicolumn{6}{|l|}{ CALiPER Testing Program } \\
\hline Product Tests & 200 Tests & 300 Tests & 400 Tests & 400 Tests & 400 Tests \\
\hline Special Investigations & 3 Investigations & 3 Investigations & 3 Investigations & 3 Investigations & 3 Investigations \\
\hline \multicolumn{6}{|l|}{ Technical Information } \\
\hline Technical Information Dev. \& Dissemination & Dev/Dissm 15 Prod & Dev/Dissm 15 Prod & Dev/Dissm 15 Prod & Dev/Dissm 15 Prod & Dev/Dissm 15 Prod \\
\hline Technical Information Network & 5 Webcasts & 5 Webcasts & 5 Webcasts & 5 Webcasts & 5 Webcasts \\
\hline \multicolumn{6}{|l|}{ Standards and Test Procedures Support } \\
\hline Standards and Test Procedures Support & 1 new std/2 update & 1 new std/2 update & 1 new std/2 update & 1 new std/1 update & 1 new std/1 update \\
\hline \multicolumn{6}{|l|}{ Coordination/Leadership } \\
\hline Local and Regional & 6 joint projects & 6 joint projects & 6 joint projects & 6 joint projects & 6 joint projects \\
\hline Federal Government & 1 major fed action & 1 major fed action & 1 major fed action & 1 major fed action & 1 major fed action \\
\hline \multicolumn{6}{|l|}{ Market Studies and Technology Evaluations } \\
\hline \multirow[t]{3}{*}{ Market Studies and Tech Evaluations } & 2Studies & 2 Studies & 2 Studies & 2 Studies & 2 Studies \\
\hline & & & & & \\
\hline & PAR38 Entrants & PAR38 Winners & TBD & TBD & TBD \\
\hline
\end{tabular}


NRC, 2010. Energy Research at DOE: Was It Worth It? Prepared by Committee on Benefits of DOE R\&D on Energy Efficiency and Fossil Energy, National Research Council. National Academy Press, Washington, D.C., 2010.

DOE, 2006. Compact Fluorescent Lighting in America: Lessons Learned on the Way to Market. Prepared for U.S. Department of Energy, Office of Energy Efficiency and Renewable Energy, Building Technologies Program. Prepared by Pacific Northwest National Laboratory. U.S. Department of Energy, Washington, D.C., June 2006.

DOE, 2011. Energy Saving Estimates of Light Emitting Diodes in Niche Lighting Applications. Prepared by Navigant Consulting for U.S. Department of Energy, Office of Energy Efficiency and Renewable Energy, Building Technologies Program, Washington, D.C., January 2011.

DOE, 2012. Solid-State Lighting Research and Development: Multi-Year Program Plan. U.S. Department of Energy, Washington, D.C., April 2012.

DOE, 2012b. Energy Savings Estimates of Light Emitting Diodes in General Illumination Applications. Prepared by Navigant Consulting for U.S. Department of Energy, Office of Energy Efficiency and Renewable Energy, Building Technologies Program, Washington, D.C., January 2012.

DOE, 2012c. 2010 U.S. Lighting Market Characterization. Prepared by Navigant Consulting for U.S. Department of Energy, Office of Energy Efficiency and Renewable Energy, Building Technologies Program, Washington, D.C., January 2012.

NGLIA \& DOE, 2011. LED Luminaire Lifetime: Recommendations for Testing and Reporting, Second Edition. Next Generation Lighting Industry Alliance and U.S. Department of Energy, Washington, D.C., June 2011. 